\section{A PERCEPÇÃO AO MEIO AMBIENTE EM ESTUDO SOCIOAMBIENTAL NA REGIÃO CENTRAL DO ESTADO DE SÃO PAULO}

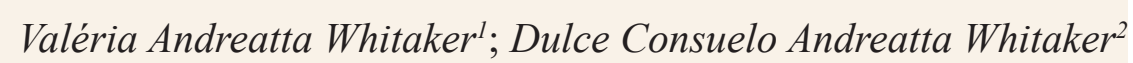 \\ Marinaldo Fernando Souza ${ }^{3}$; Zildo Gallo
}

ReSumo: A região central do estado de São Paulo contém os municípios de Araraquara, São Carlos e Ribeirão Preto e possui características ambientais tais como: manchas de solos férteis Terra Roxa, relevo ondulado e rede hidrográfica que a tornaram sujeita a ampla ocupação, com cultivos de café, laranja e cana de açúcar. Tais condições estão discutidas neste trabalho, assim como o modelo de desenvolvimento agrícola hegemônico que provoca desequilíbrios ambientais e sociais, desmatamento com perda parcial dos biomas Mata Atlântica e Cerrado, degradação do solo e dos recursos hídricos, redução da biodiversidade e homogeneidade social e agrícola. Foram apresentadas algumas alternativas a esse modelo: a pesquisa/ação do Nupedor/ NEEA que envolve propostas agroecológicas para a agricultura familiar dos assentamentos rurais de reforma agrária da região, experiências inovadoras em espaços rurais com práticas educativas e ambientais, em uma ecovila em São Carlos e na Fazenda da Toca em Itirapina. O contexto do trabalho situa ainda a passagem do Complexo Cafeeiro para o Complexo Agroindustrial da Cana e do Álcool, com transformações socioambientais causando desruralização e desurbanização.

Palavras-chave: Meio Ambiente; Desenvolvimento Agrícola; Educação; Percepção Ambiental.

'Dra. Pesquisadora do Programa de Pós-Graduação em Desenvolvimento Territorial e Meio Ambiente (Mestrado e Doutorado) da UNIARA

2Profa. Dra. do Programa de Pós-Graduação em Desenvolvimento Territorial e Meio Ambiente (Mestrado e Doutorado) da UNIARA

${ }^{3}$ Dr. pelo Programa de Educação Escolar da Faculdade de Ciências e Letras da UNESP de Araraquara

${ }^{4}$ Prof. Dr. do Programa de Pós-Graduação em Desenvolvimento Territorial e Meio Ambiente (Mestrado e Doutorado) da UNIARA
ABSTRACT: The central region of São Paulo State contains the cities Araraquara, São Carlos and Ribeirão Preto and has environmental characteristics such as Terra Roxa fertile soil patches, soft hills relief and hydrographic network that made it subject to extensive occupation, with coffee crops, orange and sugar cane. Such conditions are discussed in this paper, as well as the hegemonic agricultural development model that produce environmental and social imbalances, deforestation with partial loss of Atlantic Forest and Cerrado biomes, degradation of soil and water resources, reduction of biodiversity and social and agricultural homogeneity. Some alternatives to this model are presented: the Nupedor/NEEA project that involves agroecological proposals for the family agriculture of rural agrarian reform settlements in the region and innovative experiences in rural areas with educational and environmental practices, in an ecovillage in São Carlos and Toca Farm in Itirapina. The context of the work also places the passage from Coffee Complex to Sugarcane and Alcohol Agro-industrial Complex, with socio environmental transformations causing desruralization and desurbanization.

KeYwORDS: Environment; Agricultural Development; Education; Environmental Perception.

\section{INTRODUÇão}

A degradação ambiental acelerada e a destruição dos ecossistemas vêm provocando a perda da biodiversidade, o comprometimento do uso dos recursos naturais e o aumento da poluição do solo, da água e do ar com reflexos sobre a saúde e a qualidade de vida. O esgotamento e a poluição dos recursos hídricos podem comprometer o desenvolvimento socioeconômico e tecnológico de certas regiões.

Um novo paradigma de desenvolvimento econômico, em contraposição ao modelo dominante de utilização dos recursos naturais, pode se inspirar em novos modelos que surgem como alternativa. Esses novos modelos podem ser construídos através da visualização de atividades econômicas, a partir de iniciativas empresariais, educacionais e experiências inovadoras que representem um novo paradigma de desenvolvimento visando equilíbrio ambiental e sustentabilidade econômica. As características ecológicas, os processos de uso do solo, a qualidade e os usos múltiplos da água e a relação destes fatores com a qualidade de vida e saúde da população como um todo, 
são aspectos a serem considerados.

Como decorrência da deterioração do meio ambiente que afeta a disponibilidade e a qualidade dos recursos naturais, torna-se necessário que a sociedade desenvolva uma nova percepção da natureza.

As universidades, enquanto centros de pesquisa, são geradoras de conhecimento que podem subsidiar planos de manejo ambiental, cujo sucesso depende da percepção e inserção da perspectiva e das experiências práticas da comunidade. Esta integração depende do envolvimento e da participação da comunidade e dos setores públicos e privados da sociedade nos problemas ambientais (TUNDISI, STRASKRABA, 1995).

$\mathrm{O}$ meio acadêmico pode contribuir com este objetivo, estimulando e difundindo experiências práticas de agroecologia, atividades de agricultura orgânica e alfabetização ecológica, como uma forma de educação holística a ser aplicada em novos modelos de gestão, uso, conservação e recuperação do ambiente natural.

A educação holística pode representar uma interface integradora como ferramenta para conciliar desenvolvimento econômico e meio ambiente. Portanto, não se trata de uma educação ambiental que não transforma o desenvolvimento econômico, mas uma Educação para uma nova forma de desenvolvimento.

Uma nova visão do desenvolvimento econômico deveria englobar uma tecnologia harmonizada com valores humanos e ambientais, o quer requer descentralização e menores escalas para soluções de alguns problemas, tais como: produção de alimentos e sua dependência energética e dos recursos naturais, entre os quais solos não erodidos e não salinizados e disponibilidade de água não contaminada (ODUM, 1988).

Pensando em termos de educação holística, uma observação da realidade com olhos atentos para o que de novo está acontecendo no entorno é de suma importância. As experiências socioambientais alternativas ao modelo agropecuário introduzido pela "revolução verde", presentes na região e observadas neste artigo, têm o papel de servir como faróis àqueles que buscam saídas para o caos socioambiental produzido pela modernização da agricultura, que se seguiu após a instalação da ditadura militar no Brasil, a partir dos anos sessenta do século passado.

\section{DESCRIÇ̃̃o DA área EM ESTUDO}

A região central do estado de São Paulo, ou macrorregião central, contém as microrregiões administrativas de Araraquara, São Carlos e Ribeirão Preto, municípios que abrangem os projetos analisados neste trabalho.

“A região está inserida no Planalto Ocidental Paulista, cujo relevo é em geral levemente ondulado com predomínio de colinas amplas e baixas com topos aplanados" (ROSS, MOROZ, 2011 p 12).

O relevo pouco desgastado, os solos férteis (latossolo roxo e terra roxa devido aos afloramentos e derrames de basalto) e o clima quente e chuvoso são favoráveis às atividades agrícolas (FAPESP,1998)

Predominam duas categorias de solos no território paulista, os Latossolos e os Argissolos. Entre os primeiros estão as denominadas Terras Roxas do interior paulista, famosas pela sua fertilidade (ROSSI, OLIVEIRA, 2000, p. 23)

De acordo com Oliveira et al., (1999) na região central predominam os latossolos. Esses solos mais intemperizados são normalmente encontrados em relevos mais suaves, em posições mais estáveis e com menor taxa de erosão. Sendo favoráveis, se bem manejados, ao cultivo da cana de açúcar, laranja e café (ROSSI, OLIVEIRA, 2000).

A expansão da agricultura e o cultivo da cana de açúcar na década de 1970, início da década de 1980 e mais recentemente ocorreu sobre áreas de cerrado. As antigas áreas florestais situadas sobre os solos mais férteis, já haviam sido desmatadas, em sua maioria, no começo e em meados do século XX para dar lugar aos plantios de café e aos cultivos atuais (MIRANDA, FONSECA, 2013, p.11).

Dois biomas são predominantes no Estado de São Paulo, o Cerrado e a Mata Atlântica. A faixa de cerrados atravessa o estado no sentido nortesul, em forma de arco convexo perpassando o território de quase todos os municípios pertencentes a área central, tais como: Ribeirão Preto, Araraquara e São Carlos. Esses municípios integravam o bioma do Cerrado, mas muitos municípios destas microrregiões estão parcialmente situados em ambos biomas: do Cerrado e da Mata Atlântica. Logo, esta região situa-se numa área de transição da Mata Atlântica para o Cerrado, ou seja, numa área de Tensão Ecológica ou ecótono (MIRANDA, FONSECA, 2013).

"Há uma generalizada expansão da agricultura especialmente da cana de açúcar em toda essa região, com a permanência de remanescentes de Cerrado" (MIRANDA, FONSECA, 2013, p.16). 
A biodiversidade do estado de São Paulo está entre as mais complexas do país. Na condição original, o território era integralmente coberto pelos biomas Mata Atlântica e Cerrado. A presença destes dois biomas, junto aos demais fatores naturais, conferia riquíssima diversidade da paisagem e de formas de vida. O estado ainda possui, e mantém intactas, áreas remanescentes de Mata Atlântica, a despeito do histórico de ocupação e de atividade econômica que culminou na perda da cobertura vegetal, hoje reduzida a porções remanescentes. Esses fragmentos, em sua grande maioria estão distantes entre si, dificultando ou impedindo o fluxo gênico e suas funções ecológicas, o que compromete a conservação da biodiversidade e constitui a principal causa de extinções de espécies da fauna e flora paulistas (ESTADO DE SÃO PAULO).

O bioma do Cerrado encontra-se muito fragmentado e degradado pelo avanço das cidades, da agricultura e da pecuária. Em São Paulo, ele ocupa apenas $1 \%$ da área do Estado, da qual já cobriu 14\%. E apenas cerca da metade que restou encontra-se protegida na forma de unidades de conservação e de reserva legal. (DURRIGAN et al, 2004). O Cerrado está debilitado porque são algumas manchas de vegetação, com intenso uso e ocupação ao seu redor e essas pequenas ilhas de vegetação isoladas são muito mais frágeis. A ameaça não é apenas sobre a biodiversidade, mas também sobre os estoques do Aquífero Guarani, uma das maiores reservas de água subterrânea do mundo, uma vez que, com a substituição da vegetação nativa pela agricultura, os agrotóxicos e adubos podem chegar ao solo profundo e contaminar o aquífero. (BITENCOURT, MENDONÇA, 2004). A região central do estado está localizada numa área de recarga do Aquífero Guarani.

Araraquara e São Carlos situam-se na bacia hidrográfica Tietê/Jacaré. As principais atividades econômicas nesta região são o agronegócio (usinas de açúcar e álcool, mineração, curtumes e fundições). Os usos do solo são, portanto, caracterizados por atividade agroindustrial e agropecuária. $\mathrm{Na}$ zona rural predominam extensas culturas de cana-de-açúcar, laranja, pastagens e áreas de reflorestamento com Eucaliptus sp e Pinus sp. Na bacia hidrográfica restam apenas $11,31 \%$ de áreas de vegetação nativa que consistem em cerrados e florestas ripárias ao longo do curso dos tributários. (TUNDISI et al, 2008).

REFLEX̃̃ES SOBRE AS TRANSFORMAÇÕES AMBIENTAIS E SOCIOECONÔMICAS DA REGIÃo

Este tópico é resultado de uma discussão dos autores deste trabalho, daí seu caráter ensaístico. Constitui-se uma contribuição original que correlaciona as informações dos estudos citados no tópico anterior "Descrição da área em estudo" e representa conhecimentos que discutimos sobre diferentes campos entrelaçados: ambiental, histórico, econômico e social.

A topografia de relevo relativamente suave, caracterizado pelas colinas e solos férteis com as manchas de Terra Roxa, cujas propriedades são ideais para o cultivo do café, foi um dos fatores motivadores da marcha do café na direção do interior paulista durante o século XIX.

Alterações antrópicas significativas ocorreram a partir do ciclo do café nesta região, que era até então bem preservada em contraste com as áreas litorâneas e mineiras, onde os ciclos do ouro e da cana de açúcar já haviam produzido fortes impactos sobre os ecossistemas, com perda significativa da vegetação original nos séculos anteriores.

A primeira fase do desmatamento, na região paulista, aconteceu através da instalação das fazendas de café e expansão das ferrovias, sendo a madeira usada para os dormentes e produção de energia das fornalhas. É importante ressaltar que a perda da biodiversidade deve ter sido acentuada nesta região, pelo fato dela representar a transição de dois biomas: o da Mata Atlântica e o do Cerrado, uma vez que, em áreas ecotônicas de transição, a biodiversidade é ainda mais elevada.

A partir do processo de urbanização da década de sessenta, com o surgimento das cidades de porte médio, o cultivo de laranja na década de setenta, e a posterior expansão da monocultura da cana de açúcar e do agronegócio nos anos noventa, vão intensificando as mudanças no perfil do território.

A perda da biodiversidade no meio rural tornou-se irreversível: os remanescentes da vegetação original são poucos e em pequenas áreas que representam fragmentos isolados, nos quais o valor destes como "pool" gênico torna-se ainda maior. Tais fragmentos funcionam como microssistemas isolados dentro de um macro sistema bem degradado pela paisagem dominada pela monocultura da cana de açúcar. A carência de mata ciliar e as reservas legais, isoladas como ilhas, cercadas pela cana, muitas vezes sem conexão com a mata ciliar, já fragmentada e não contínua, bloqueia o fluxo gênico e de informação na cadeia ecológica. Tais processos foram analisados por Durrigan et al, 2004 e Miranda e Fonseca, 2013.

O processo de redução da biodiversidade certamente afetou os cursos de 
água, que sofrem, tanto a poluição urbana, como a agrícola: agrotóxicos, fertilizantes químicos e principalmente o vinhoto que foi lançado durante anos nos rios da região, cujo maior impacto é derivado da agricultura (conforme descrito por Bintencourt e Mendonça, 2004); em contraposição às áreas de maior adensamento urbano e concentração de indústrias em outras regiões.

A queimada dos restos culturais da cana de açúcar, praticada durantes anos, foi ainda um agravante da monocultura sobre a biodiversidade dos ecossistemas adjacentes, os quais muitas vezes sofreram os efeitos direta ou indiretamente desta ação; além da exaustão do solo pelo cultivo ininterrupto e queima dos resíduos orgânicos da sua superfície.

As consequências sociais e culturais da monocultura da cana de açúcar, que foram extensamente estudadas por D'Íncao, 1972; Whitaker, 1984; Whitaker, 2006; produziram uma maior homogeneidade social na configuração rural local, caracterizando a região agrícola como rica em relação ao aspecto da exportação, mas pouco diversificada na produção agrícola. A região possui uma pobre diversidade produtiva, sendo importadora de alimentos a longa distância.

Este modelo implicou num empobrecimento, em vários níveis sistêmicos, da cadeia produtiva, da baixa diversidade agrícola dos produtos até no nível das variedades e das sementes, o que provoca uma maior vulnerabilidade e riscos para o agricultor em relação às variações econômicas e ambientais, apesar do alto valor comercial dos produtos de exportação, no caso da cana de açúcar e da laranja.

Ora, transformações em qualquer ecossistema, repercutem necessariamente na cultura dos grupos humanos que vivem em consonância - imbricados, influenciados ou até mesmo condicionados - pelo ecossistema em questão. São processos, ao mesmo tempo ambientais e socioculturais. (WHITAKER, 2006)

No caso da região em pauta, foi possível observar esse tipo de transformação e os problemas sociais decorrentes, quando da passagem do Complexo Cafeeiro para o Complexo Agroindustrial da Cana e do Álcool, que se acentuou na segunda metade do século XX.

Com efeito, as antigas fazendas de café da região - formadas a partir do século XIX, quando o país se tornou o grande produtor mundial - nunca foram, segundo a historiadora araraquarense Ana Maria Martinez (1967), formadoras de latifúndios. Eram fazendas de porte médio, e concentravam numerosa população de colonos, imigrantes ou seus descendentes, que garantiam uma enorme diversidade agrícola, o que está bem documentado do ponto de vista histórico (por exemplo, o excelente álbum de Araraquara de 1915 traz minuciosas descrições das aristocráticas fazendas da região, nas quais imperava extraordinária diversidade agrícola). É óbvio que a vida desses colonos não era fácil e numerosa bibliografia registra a exploração de que eram vítimas. Mas como dispunham sempre de um lote para seus plantios, tinham grande fartura de alimentos e relativa autonomia - além da autoridade que exerciam os mais velhos sobre membros da família (o que pode ser analisado também como autoritarismo ou repressão, mas não nos cabe analisar aqui). Do ponto de vista socioambiental, no entanto, havia certo equilíbrio, uma vez que os patrões permaneciam na fazenda e produzia-se ali a maior parte do que se comia (frutas de todos os tipos e animais de diferentes espécies em relações sistêmicas). Havia então um modo de vida menos agressivo, que além de não destruir completamente as florestas, substituía a biodiversidade "invadida" por diversidade agrícola baseada na policultura e na criação, ou seja, na produção de alimentos, mais próxima do ecossistema "invadido".

Uma população rural expressiva exercia então uma pressão positiva sobre a urbanização nas pequenas cidades que lhes forneciam os serviços religiosos e de comércio, e até mesmo médicos, odontológicos e de hotelaria - o que foi bem estudado por Whitaker (1984) no caso de Santa Lúcia, pequena cidade da região, rodeada por fazendas de café.

Com a substituição do complexo cafeeiro pela cana - o café migrando na marcha mais a oeste e o pró álcool estimulando a monocultura de canadesintegrou-se o colonato, e a rica diversidade agrícola que o caracterizava foi suprimida. Amonocultura com as características discutidas na introdução deste artigo, foi acompanhada do aprofundamento da devastação do meio ambiente e as transformações sociais foram dramáticas. Os colonos foram tangidos pelo êxodo rural, abandonaram as fazendas e quando os velhos fazendeiros morreram, seus filhos e netos arrendaram as terras para o plantio de cana.

Surge o trabalhador volante, morador das cidades, mas que tem que ir ao campo para exaustivas jornadas de trabalho (e que entra para uma nova categoria sociológica, sob o conceito de "boia fria"). (D'ÍNCAO, 1972)

Resumindo: ocorre um rápido processo de desruralização e de desurbanização. Que seja: dissolvem-se as estruturas patriarcais no campo e desurbanizam-se as pequenas cidades, transformando-se em "dormitórios" de trabalhadores rurais. 
Marginalização, cidades inchadas, periferias urbanas sem planejamento, enfim, dramáticas transformações, com a desorganização das pequenas cidades, já que a produção de commodities repercute mais favoravelmente nos grandes centros urbanizando-os, mas esvazia as "aldeias” (MORSE, 1975)

Não se pode esquecer que todos esses fenômenos ocorrem dentro de uma totalidade histórica: um país do Terceiro Mundo em processo acelerado de industrialização, passando a produzir bens de capital, com mudanças sociais em todas as regiões, cada uma com suas especificidades. O processo porém é excludente. Instalam-se poderosas multinacionais, com abundância de capitais que aprofundam nossa dívida externa. Ficamos então sob o domínio da ideologia do Brasil Potência: o famoso milagre brasileiro, que rapidamente daria origem à "Crise do Milagre". (SINGER, 1976).

Tais os efeitos dramáticos da transição nos modelos hegemônicos: de um modelo menos devastador sobre o ecossistema - o Complexo Cafeeiro, com sua diversidade agrícola - para o modelo "agrobussiness" que o desarticula e destrói os fragmentos do ecossistema original, implantando a monocultura como ideal de modernidade e produtividade.

Nesse sentido, os exemplos e estudos de casos que serão mostrados neste trabalho são relevantes porque vão na direção contrária ao modelo hegemônico de desenvolvimento da região, baseado na monocultura. E podem, portanto, despertar uma nova percepção do meio ambiente, como nas seguintes experiências.

EXPERIÊNCIAS ATUAIS SOCIOECONÔMICAS E AMBIENTAIS ALTERNATIVAS NA REGIÃo

O Núcleo de Pesquisa em Desenvolvimento e Documentação Rural (Nupedor) da Uniara, vem há anos estudando a agricultura familiar dos assentamentos rurais de reforma agrária da região. Algumas inciativas espontâneas por parte dos assentados relativas à diversificação agrícola, ao manejo do solo (preservação da matéria orgânica) e à recomposição da vegetação foram observadas nas pesquisas de campo (WHITAKER et al, 2011). Sendo assim, um projeto conjunto do Nupedor com o Núcleo de Estudos e Extensão em Agroecologia (NEEA), ambos do programa de pós-graduação em Desenvolvimento Territorial e Meio Ambiente da Uniara, em ação com outros órgãos implementou a Pesquisa-ação e construção de proposta agroecológica para a agricultura familiar da região central do estado de São Paulo sob coordenação da Dra Vera Lúcia Silveira Botta
Ferrante.

A região de atuação deste projeto constitui os assentamentos de reforma agrária localizados nas microrregiões de Araraquara, São Carlos e Ribeirão Preto. O projeto tem como relevância estimular a prática da produção diversificada e não convencional neste território da região central do Estado de São Paulo, caracterizado pela produção de monocultura de cana-deaçúcar e laranja, uso intensivo de agrotóxicos e sistemas produtivos com baixa demanda e capacidade de ocupação de força de trabalho. Estes dois monocultivos expulsaram a agricultura de alimentos, os quais por sua vez, têm que ser importados, o que implica em gastos com o seu transporte e a perda de hábitos alimentares locais. Também o desmatamento teve influência sobre o microclima regional, a conservação dos solos e a conservação dos recursos hídricos. (NUPEDOR; NEEA, 2017)

Os resultados e atuações desse projeto foram em vários domínios ambientais, sociais, econômicos e educacionais, tais como: a produção de hortaliças orgânicas e o desenvolvimento de estratégias de comercialização e ações para a obtenção do selo de certificação; a criação de uma feira de orgânicos com o fortalecimento da transição agroecológica; uma ação junto à rede municipal de educação para a instalação de horta educacional; a regularização da comercialização da produção orgânica e da venda institucional através do Programa de Aquisição de Alimentos (PAA) e do Programa Nacional de Alimentação Escolar (PNAE). Registra-se ainda, a produção de galinhas em sistemas agroecológicos na Cooperativa de Produtores Assentados de Motuca, num processo de transição da produção convencional de aves e ovos para uma produção tipo caipira e baseada em alimentos agroecológicos. Esta ação ocorre em parceria com a ESALQ-USP, o Instituto de Terras do Estado de São Paulo (ITESP) e o Instituto Federal de São Paulo (IFSP) campus Matão. Importante lembrar a construção de uma unidade experimental dentro de um lote de assentamento, em caráter demonstrativo de um sistema de produção caipira e orgânico, com a realização de cursos de capacitação e a implementação de uma unidade experimental de avicultura no Assentamento Monte Alegre.

Caravanas agroecológicas foram realizadas promovendo ações educativas com professores e alunos nas escolas de Araraquara/SP em apoio à construção de valores e saberes ligados à sustentabilidade, através de visitas a sítios agroecológicos. O projeto tem parceria com a ESALQUSP, INCRA-SP, Coordenadoria de Assistência Técnica Integral (CATI), 
Federação da Agricultura Familiar do Estado de São Paulo (FAF), IFSP campus Matão, Fundação Mokiti Okada, ONG Iniciativa Verde e com o Serviço Social do Comércio - SESC Araraquara. Os alunos visitaram dois lotes do Bela Vista do Chibarro e o Projeto Curumim-SESC. Uma visita à Fazenda da Toca, de produção agroecológica diversificada, localizada em Itirapina-SP, foi organizada.

A lista de atividades é ainda longa, em resumo: Instalação de um sistema silvipastoril em área de recuperação de pastagem degradada no assentamento Monte Alegre. Conversão de uma lavoura cafeeira convencional para um sistema agroflorestal cafeeiro, numa área de antiga lavoura convencional no assentamento Santa Helena, no município de São Carlos. Realização de cursos e palestras sobre o manejo agroecológico do solo, com destaque no caso do sistema silvipastoril, no controle da erosão de solos. Implementação de um sistema agroflorestal em um lote no Assentamento Bela Vista do Chibarro. Implementação de uma unidade de produção, beneficiamento e comercialização de ervas medicinais no Assentamento Monte Alegre, com a recuperação e valorização do conhecimento de plantas medicinais e medicina tradicional das mulheres assentadas. Incorporação deste saber nas práticas agroecológicas, com a sistematização do uso no controle de pragas e de doenças na agricultura, assim como, a comercialização desses produtos sob a forma desidratada. Implantação de uma área experimental de adubação verde no Instituto de Biotecnologia da UNIARA, um centro de estudos interdisciplinares que desenvolve programas de ensino, pesquisa, desenvolvimento tecnológico, extensão e serviços. Nesta área realizou-se o plantio de adubos verdes de verão (crotalária, guandu e mucuna preta) e de inverno (tremoço, aveia preta e ervilhaca) para avaliar o comportamento de tais espécies na região, e produção de sementes que estão sendo distribuídas aos agricultores para serem avaliadas em campo. Iniciou-se a validação tecnológica sobre o cultivo de hortaliças em manejo agroecológico. $\mathrm{Na}$ área da fruticultura instalou-se um pomar diversificado para se avaliar o comportamento das espécies às condições edafoclimáticas locais em manejo agroecológico. Elaboração dos biofertilizantes, compostagem e microrganismos eficazes e realização de cursos em todos os assentamentos do projeto.

Os realizadores do projeto consideraram que tais tecnologias sociais compreendidas como um conjunto de técnicas e metodologias transformadoras, desenvolvidas e/ou aplicadas na interação com a população e apropriadas por ela, representam soluções para inclusão social e melhoria das condições de vida. (FERRANTE, apud NUPEDOR; NEEA, 2017). Salientando-se que elas também atuam na soberania e na segurança alimentar dos assentados envolvidos, além de representarem modelos de cultivos e uso do solo que melhoram a saúde da população e a condição do meio ambiente em geral, nas áreas de implementação do projeto.

Neste sentido, a sociedade tem buscado - em diferentes setores sociais - modelos alternativos de produção e de vida social, que chamam atenção pela criatividade e demonstram percepção aguda de seus realizadores da necessidade de mudanças que estamos propondo.

\section{EXPERIÊNCIAS ENCONTRADAS EM PESQUISA CIENTÍFICA NA REGIÃo}

Em sua tese de doutorado, Souza (2016) pesquisou práticas educativas em espaços rurais da região Central do Estado de São Paulo nas cidades de São Carlos e Itirapina. O autor apresentou duas experiências educacionais, chamando-as de "singularidades educacionais alternativas aos modelos hegemônicos de escolarização formal". Seus estudos contribuem com as premissas centrais deste artigo, na medida em que demonstra e defende possibilidades educacionais que podem contribuir para a formação de pessoas com percepção profunda de meio ambiente, capazes de transitar e equacionar um dos grandes desafios da sociedade contemporânea: o equilíbrio ambiental e a sustentabilidade econômica. Concordamos com Souza (2016, p.67) quando afirma que "estudar essas singularidades que são orientadas dentro de novos conceitos de matriz de sustentabilidade, pode fornecer às Ciências - e aqui destacamos a Educação como chave de transição - novas possibilidades de desenvolvimento comunitário rural e urbano, tanto na dimensão socioeconômica, como na ambiental, cultural e educacional".

Destacaremos inicialmente o caso exemplar da Ecovila Tibá. Localizada a dezessete quilômetros do centro de São Carlos S.P, a ecovila é um espaço rural associativo de onze alqueires fundado no ano de 2006. Como descreve Souza (2016), "são pessoas que "desistem" da vida exclusivamente urbana e que levam suas preocupações com a educação, com o meio ambiente e com a própria qualidade de vida a consequências de alta coerência". No local há aproximadamente trinta moradores, entre famílias permanentes e visitantes em sistema de residência temporária, todos em fluxo constante para troca de experiências em educação permanente sobre temas de 
interesse. Suas produções materiais e simbólicas estão estreitamente ligadas aos fundamentos agroecológicos e permaculturais. O objetivo dos fundadores foi proporcionar condições para o desenvolvimento de um estilo de vida sustentável e "espaço de produção e reprodução de condições materiais e simbólicas voltadas para a vida no campo". Portanto, repensar o consumo, preservação e recuperação da natureza, trabalho solidário, fortalecimento e reconexão espiritual, com foco nos processos educativos para a sustentabilidade, são premissas fundamentais da práxis tibaporá. Esse fenômeno de retorno das pessoas e de suas famílias para o rural, realizando atividades diversificadas, organizadas em redes, que buscam modos de vida sustentável, incluindo a alternância entre o convívio urbano e rural, é o que Silva e Hoffmann, (2001) e Souza, Whitaker e Whitaker (2015) têm conceituado como o Novo Rural.

Já cabe ressaltar que a Ecovila não é um espaço educativo formal tal como encontramos nas escolas tradicionais. O que interessou ao pesquisador, foi o que ele chamou de "grande painel filosófico educacional" com infinitas possibilidades e interações que fazem emergir um grande caleidoscópio de práticas que vão além da relação de ensino e aprendizagem da escolarização formal. Utilizando-se do método etnográfico, pergunta: quem os tibaporás pensam que são? o que eles pensam que estão fazendo? quais os objetivos daquilo que eles pensam que estão fazendo? As respostas são verdadeiras rupturas e reencontros com antigas práticas humanizadoras, o que faz emergir infinitas reflexões para uma educação que leve a uma percepção ambiental profunda.

Neste contexto, um ambiente que poderia inicialmente parecer caótico revela preocupações importantes com os processos educativos informais e não-formais, além de organizações que podem inspirar os ambientes educacionais. Quaisquer atividades representam uma possibilidade educativa, seja o livre brincar, as atividades extraescolares com educadores, uma reunião de adultos, o cuidar dos animais, o roçado do campo, a preparação da comida, a recepção de pessoas ou uma cerimônia espiritual. Há uma intencionalidade que demarca o espaço educativo e, evidentemente nada parecido com as estruturas racionais dos currículos e projetos políticos pedagógicos das escolas formais. Como aponta Souza (2016), os vícios acadêmicos acabam levando pesquisadores a exageros na qualificação, quantificação e enquadramento das práticas educativas "como se tudo tivesse que ser nomeado, encaixotado e levado para consumo", mas cumpre ressaltar a preocupação dos tibaporás em não apontar marcas indeléveis em suas práticas educativas para a comunidade. Apesar da inspiração na Filosofia das Diferenças de Deleuze e Guattari, na Educação como Prática de Liberdade de Paulo Freire ou das Pedagogias Libertárias Anarquistas, a maior preocupação é deixar espaços para o diálogo permanente, que justifique a fluidez criativa e apague quaisquer posições dogmáticas ou sectárias. Apresenta-se, portanto como uma alternativa educativa integradora que permite olhares complexos para os fenômenos socioambientais. Souza (2016) alerta que os processos educativos na ecovila "não estão desvinculados da cultura científica, mas são dialogados com os saberes populares profundos, objetivando criar condições de enfrentamento das ideologias dos sistemas de exploração capitalista". Tal como afirma Whitaker (2008, p.286) é necessário que os ambientes educativos - ou exatamente a escola - urbanos ou rurais, estabeleçam condições de reconexão entre "os conteúdos culturais hegemônicos e aqueles que parecem "menores", que além de existirem em maior quantidade, são os que sustentam e caracterizam uma população que foi rural até poucas décadas. $\mathrm{O}$ estabelecimento dessas pontes garantirá a proteção da cultura e do ecossistema".

O nosso segundo destaque é para a Escola de Educação Infantil na cidade de Itirapina, localizada na Fazenda da Toca, que é uma grande propriedade rural voltada para produção de orgânicos e manejo agroflorestal em larga escala. A Fazenda da Toca está localizada na cidade de Itirapina - a $200 \mathrm{~km}$ de São Paulo - e ocupa uma área de 2300 hectares, que por muito tempo foi utilizada para a monocultura da laranja. Há quarenta anos a propriedade pertence à família do empresário Abílio Diniz, bastante conhecido pela gestão de grandes corporações do ramo varejista e processamento de alimentos. Desde o ano de 2009, a fazenda vem passando por transformações e colocando em prática os seus projetos sustentáveis de agricultura orgânica e indústria de alimentos, investindo na educação e pesquisa em vários setores. $\mathrm{O}$ objetivo central foi confrontar a lógica do agronegócio monocultor e destruidor do ecossistema, implantando gradativamente um contexto educativo apoiado pelas teorias sistêmicas e pelos conhecimentos e práticas agroecológicas e permaculturais. Talvez, os dois setores com maior visibilidade e sucesso, sejam justamente a Escola e os Sistemas Agroflorestais em larga escala, ambos com forte tendência para a formação de pessoas com percepções ambientais profundas. Como sugere Souza (2016), passaram a adotar novas tendências filosóficas, politicas, sociais 
e econômicas, que pudessem apoiar este movimento de transição de um modelo produtivo linear, fragmentado e mecânico, para um grande sistema ecológico, interdependente e cooperativo. Pensando na organização rural, o autor chama a atenção para um rural tradicional em transição, com novas características de gestão e de convívio, no qual podem ser encontradas, tanto as características de um Novo Rural agroecológico como o emergir de uma ruralidade nomeada como um Rural Paradoxal: como harmonizar os interesses econômicos, os processos de educação e a sustentabilidade ambiental?

[...] por um lado a necessidade de lucro imediato em um mundo cada vez mais veloz, voraz, produtivista, globalizado e competitivo, por outro a necessidade de harmonizar sustento econômico, rentabilidade, tempo, recuperação e preservação do meio ambiente e sustentabilidade (SOUZA, 2016, p.34)

Essas transformações começaram a inserir a fazenda em uma grande rede de fomento aos estudos e aplicações educativas e empresariais inovadoras, que estimulam a emergência em todo o mundo de novas estruturas de propriedade como alternativas às estruturas corporativas dominantes - uma crescente revolução da propriedade (CAPRA, 2014). No caso brasileiro, é uma tendência que vem ganhando cada vez mais adeptos no mundo empresarial e que já é uma realidade que mostra sua efervescência em milhares de experiência comunitárias em forma de Ecovilas que são verdadeiras "Revoluções Moleculares que buscam uma articulação éticopolítica entre os três registros ecológicos: o do meio ambiente, o das relações sociais e o da subjetividade humana" (GUATTARI, 1995).

No "Contexto Toca", Souza (2016) coloca foco nos processos educativos da Escola da Toca, que na época recebia crianças apenas para educação infantil. Tinha a capacidade para atender setenta crianças de dois a seis anos de idade, mas estava atendendo cerca de quarenta, divididas em turmas multisseriadas no período da manhã e da tarde, acompanhadas por três educadores e educadoras em cada turno. A escola foi criada em 2008, em formato de creche, para atender as famílias de trabalhadores residentes na fazenda. Foi nesta época também que começaram a surgir as primeiras ações de transição da Fazenda para a produção agrícola diversificada, orgânica e agroecológica. Toda essa transição material e filosófica, também trouxe uma série de demandas e desafios que foram amplamente debatidos e fortalecidos, resultando na criação do Instituto Toca que colocou foco na aprendizagem e na pesquisa, a partir do trabalho com a educação formal e não-formal, vivências educativas, cursos e projetos de integração com a comunidade.

Essas primeiras experiências educacionais da Escola da Toca, em 2008, foram vivenciadas ainda na época da produção convencional da laranja. Foi a partir deste momento que começaram a surgir as ideias embrionárias de formação do Instituto Toca - 2012 - responsável por pensar e implementar o contexto de educação e pesquisa da Fazenda. Tal como descreve Souza (2016), "passou a funcionar a partir de três frentes principais, que é a Escola Toca do Futuro com o trabalho de educação formal, o programa Sementes da Toca de educação não-formal e o programa de desenvolvimento e capacitação de pessoas através do Centro de Estudos e Vivências Ambientais"

Este foi também foi o momento em que os núcleos voltados para o debate educacional começam a delinear o painel filosófico-educacional que poderia atender aos objetivos centrais de uma educação para a sustentabilidade, como elemento primordial para a percepção ambiental.

Desta forma, além de realizar diálogos transdisciplinares com importantes teorias da Psicologia e da Educação, a reorganização educacional apoiouse principalmente na Teoria Sistêmica e nos princípios da "alfabetização ecológica" de Fritjof Capra e (cols.) que, de forma geral:

[...] incorpora os princípios do pensamento relacional da ecologia e do olhar sistêmico, não como uma disciplina isolada, mas como estratégia de entrelaçamento desses princípios com os conteúdos dos seus currículos. É um olhar sistêmico para os processos educativos e que pode ser empregado em quaisquer etapas dos métodos de ensino formal escolarizado que conhecemos, ou nos mais variados contextos educativos (SOUZA, 2016, p.102).

É evidente que não temos a pretensão de abordar todo o vasto empreendimento teórico das Teorias Sistêmicas ou da ecoalfabetização. Mas é importante ressaltar que ambas têm como foco a observação complexa entre as relações, os padrões e o contextos, que dão sinais de como a natureza sustenta a Teia da Vida (CAPRA, 2006) e (CAPRA; LUIGI, 2014).

O importante para nós aqui, é perceber o quanto esta metodologia pode provocar a capacidade de uma pessoa desenvolver a inteligência ecológica e a mudança dos pontos de vista fragmentados e mecanicistas: "das partes 
para o todo, dos objetos para as relações, do conhecimento objetivo para o conhecimento contextual, da quantidade para a qualidade, da estrutura para o processo, dos conteúdos para os padrões" (CAPRA, 2006).

Como estratégia para o fortalecimento da educação para uma ecologia profunda, as experiências educacionais - a exemplo das que foram apresentadas - precisam subverter a condição de isolamento e realizar conexões promovendo a sensibilização necessária para a superação das estruturas conservadoras. Ou seja, ampliar experiências singulares e percepções profundas de proteção ao meio ambiente.

Apesar dos obstáculos advindos da fúria produtivista do sistema, acreditamos numa educação com reflexão profunda sobre o meio ambiente, produzindo novas subjetividades, influindo também na diminuição de injustiças e desigualdades sociais.

\section{CONSIDERAÇÕES FINAIS}

O processo de modernização acelerada com a transformação drástica da agricultura em países do Terceiro Mundo vem ameaçando a diversidade em vários níveis sistêmicos: desde o nível genético e biológico relativo às espécies, variedades, raças de plantas e animais cultivados até no nível paisagístico e cultural. A estabilidade e a sustentabilidade da agricultura tradicional são baseadas na diversidade da produção agrícola. A menor uniformidade dos plantios, apesar de uma menor produtividade para o agricultor, fornece uma margem extra para a resistência às pragas, doenças, outros riscos ambientais e condições econômicas incertas. As monoculturas criadas longe do centro de origem tendem a apresentar defesas genéticas mais simples contra patogenias e pragas, com safras mais vulneráveis ao ataque de epidemias quando comparadas com agro ecossistemas tradicionais (ALTIERE e MERRIC,1997).

Segundo Dugan (1994), as pressões do desenvolvimento urbano, industrial e sobretudo agrícola sobre os ecossistemas estão promovendo a pobreza e a marginalização social das comunidades rurais, devido à substituição do uso sustentável dos recursos pela conversão em uma agricultura custosa energeticamente e ineficiente em relação ao uso dos recursos naturais. As consequências ambientais deste fenômeno são a erosão, a salinização, a acidificação e a perda da fertilidade do solo, a perda de ecossistemas, da biodiversidade e das funções ecológicas; além da perda da diversidade cultural, e fonte de alimento e de renda das comunidades, com resultante pressão da população sobre o meio urbano. A manutenção dos processos e funções ecológicas dos ecossistemas é de interesse para a sociedade do ponto de vista sócio econômico e do desenvolvimento econômico. Portanto, a preservação da diversidade física e biológica é fundamental para a população, seja a rural que conserva sua fonte de recursos e sobrevivência, seja a urbana que recupera a qualidade dos recursos naturais que consomem.

Este trabalho apresentou uma caracterização socioambiental da região central do Estado de São Paulo, mostrando a sua importância relativa aos biomas originais e a presença do aquífero guarani; assim como os principais ciclos econômicos do café, laranja e cana de açúcar que determinaram o modelo hegemônico de desenvolvimento agrícola, com base na monocultura, que causaram inúmeros impactos ambientais e sociais. Foram apresentadas alternativas a este modelo destruidor da natureza e das relações sociais em assentamentos de reforma agrária, envolvendo iniciativa variadas de agroecologia para a agricultura familiar. Outras experiências sociais e educacionais inovadoras de sustentabilidade econômica e ambiental numa ecovila em São Carlos e na Fazenda da Toca em Itirapina foram apresentadas como possibilidades de um novo rural. Processos tanto de educação formal, como informal nestes espaços rurais, foram discutidos através da percepção dos seus atores sociais e da população urbana, em relação ao desenvolvimento e ao meio ambiente da região.

Este artigo é mais um dos muitos que se colocam no sentido de divulgar novas possibilidades de trajetórias diferenciadas para o desenvolvimento regional que caminham na contramão do modelo concentrador de propriedades, de renda e destruidor do meio ambiente. É mais um, mas nunca será demais, pois a mudança de rumo é urgente e cada vez mais necessária frente aos crescentes riscos que a humanidade e todo o Planeta estão sujeitos neste momento ímpar da história do mundo.

Os estudos de casos diferenciados de uso e ocupação do território para a produção de alimentos ambiental e socialmente corretos, quando iluminados e expostos à luz do dia, servem como estímulos para que novos casos aconteçam. Não se trata de pregar no deserto, pois os casos apreciados são verdadeiros e perfeitamente replicáveis, principalmente pela agricultura familiar, que é mais adaptável à policultura por conta da sua escala produtiva menos extensa e extensiva.

Nestes tempos hegemonizados pela produção agrícola monocultural e agressiva ao meio ambiente, a divulgação de experiências bem sucedidas, 
que apontam no sentido contrário do consenso (mito) pré-fabricado pelo grande capital agropecuário de que a radical modernização conservadora do campo no Brasil garantiria a produção de alimentos para a população local e para a exportação (a ideia do Brasil como celeiro do mundo), é necessária e bastante educativa, no mais claro sentido da educação pelo exemplo. Lançar olhares sobre o novo e percebê-lo como viável sempre será um bom caminho; esta foi a intenção primeira da construção deste artigo.

\section{REFERÊNCIAS}

ALTIERI, M. A.; MERRICK, L. C. Agroecologia e conservação in situ da diversidade de plantações nativas no Terceiro Mundo. In: WILSON, E.O. (org). Biodiversidade. Pp. 462-473. Rio de Janeiro: Editora Nova Fronteira, 1997.999

BITENCOURT, M. D.; MENDONÇA, R. R. Viabilidade de conservação dos remanescentes de cerrado no Estado de São Paulo. São Paulo: AnnaBlume, 2004. 169 p.

CAPRA, Fritjoj et al. Alfabetização Ecológica: a educação das crianças para um mundo sustentável. São Paulo: Cultrix, 2006. 318 p.

CAPRA, F. A Teia da Vida. São Paulo: Cultrix, 2008.

CAPRA, Fritjof; LUISI, Pier Luigi. A Visão Sistêmica da Vida: uma concepção unificada e suas implicações filosóficas, políticas, sociais e econômicas. São Paulo: Cultrix - Amana-key, 2014. 615p.

D’INCAO, M. C. O Boia-Fria: acumulação e miséria. Petrópolis: VOZES, 1972. $154 \mathrm{p}$

DUGAN, P. J. Wetlands in the 21th century: the challenge to conservation science. In: MITSCH, W. J. (Ed) Global Wetlands: Old Word and New. Pp.75-87. Elsevier Science, 1994.

DURIGAN, G; FRANCO, G.A.D.C; SIQUEIRA, M.F. A vegetação dos remanescentes de cerrado no Estado de São Paulo. In: BITENCOURT M.D. \& MENDONÇA R.R. (orgs.). Viabilidade de conservação dos remanescentes de cerrado no Estado de São Paulo. Pp. 29-56. São Paulo: Annablume, 2004.

ESTADO DE SÃO PAULO. A Biodiversidade no Estado de São Paulo. Disponível em Portaldabiodiversidade.sp.gov.br/a-biodiversidade-noestado-de-sao-paulo. Acesso em 03/05/2018.

FAPESP (FUNDAÇÃO DE AMPARO À PESQUISA DO ESTADO DE SÃO PAULO). O novo mapa de relevo paulista. Revista Pesquisa Fapesp Ed. 35 Setembro, Pp 14-15.1998. Disponível em fapesp35-14-site.pdf. Acesso em 03/05/2018.

GUATTARI, F. As três ecologias. 5. ed. Campinas: Papirus, 1995. 56 p.

MARTINEZ CORREIA, A. M. História Social de Araraquara 1817 a 1930 (mímeo), 1967

MIRANDA, E. E.; FONSECA, M. F. Considerações fitogeográficas e históricas sobre o bioma cerrado no Estado de São Paulo. Embrapa Nota 1 Técnica Campinas, SP. Dezembro, 2013. 30 p

MORSE, R. Evolução das cidades latino americanas. Cadernos CEBRAE no 22, São Paulo, 1975.

ODUM, E.P. Ecologia. Rio de Janeiro: Guanabara, 1988. 434 p.

OLIVEIRA, J.B.; CAMARGO, M.N.; ROSSI, M. \& CALDERANO FILHO, B. Mapa pedológico do Estado de São Paulo: legenda expandida. Instituto Agronômico/EMBRAPA Solos. Campinas. 1999. 64p

NUPEDOR (Núcleo de Pesquisa em Desenvolvimento e Documentação Rural); NEEA (Núcleo de Estudos e Extensão em Agroecologia). Relatório Técnico CNPq n. 39/2014 Pesquisa-ação e construção de proposta agroecológica para a agricultura familiar da região central do Estado de São Paulo. UNIARA. Araraquara /SP. 2017. 
ROSSI, M.; OLIVEIRA, J. B. O mapa pedológico do Estado de São Paulo O Agronômico, Campinas, v. 52, n.1, Pp 21-23. 2000.

ROSS, J. L. S.; MOROZ, I. C. Mapa Geomorfológico do Estado de São Paulo. Revista do Departamento de Geografia, São Paulo, v. 10, Pp. 41-58, 2011.

SINGER, P. A Crise do Milagre. São Paulo: Paz e Terra, 1976. 168 p.

SILVA, J. F. G.; HOFFMANN, R. Caracterização do Novo Rural Brasileiro: 1992 - 1998 / fase III. Pesquisa Fapesp, São Paulo, v. 0, n. 0, p.14-17, 01 out. 2001. Mensal.

SOUZA, M. F.; WHITAKER, V. A.; WHITAKER,D. C. A.. Configurações Rurais: estudo comparativo de modelos alternativos. Retratos de Assentamentos, Araraquara, v. 17, n. 2, p.117-127, 12 dez. 2015. Semestral

SOUZA, M. F. Além da Escola: reflexões teórico-metodológicas com base na análise de práticas educativas alternativas descobertas em áreas rurais da região de São Carlos S.P. 2016. 192 f. Tese (Doutorado) - Curso de Educação Escolar, Universidade Estadual Paulista - Unesp, Araraquara, 2016.

TUNDISI, J. G.; MATSUMARA-TUNDISI, T.; D. C. P., A. P. L., Paulo H. Von Haeling e Eduardo H. Frollini. A bacia hidrográfica do Tietê/Jacaré: estudo de caso em pesquisa e gerenciamento. Estudos Avançados, v. 22, n.63, Pp159-172. 2008.

TUNDISI, J. G.; STRASKRABA, M. Strategies for building partnerships in the context of rivers management: the role of ecotechnology and ecological engeneering. Lakes and Reservoir: Research and Management, v.1, Pp 31-38, 1995.

WHITAKER, D. C. A. Ideologia e Práticas Culturais: O controle ideológico dos trabalhadores da cana. São Paulo USP. Faculdade de Filosofia, Letras e Ciências Humanas, 1984 (Tese de Doutorado).

WHITAKeR, D. C. A.; BEZZON, L. C. A Cultura e o Ecossistema.
Campinas: Alínea, 2006.

WHITAKER, D. C. A. O Rural-urbano e a escola brasileira. Retratos de Assentamentos, Araraquara, v. 1, n. 11, p.283-294, 01 out. 2008. Semestral.

WHITAKER, V. A.; WHITAKER, D. C. A.; SOUZA, M. F. de. Subjetividade, Ciência e Natureza. In: FERRANTE. V. L; DE LORENZO H.C.; RIBEIRO M. L.; TEXEIRA, D.; NUNES, L. Desenvolvimento Regional e Meio Ambiente: Os Desafios da Interdisciplinaridade. Programa de Mestrado em Desenvolvimento Regional e Meio Ambiente do Centro Universitário Araraquara. Pp 9 - 23 PUBLIT Soluções Editoriais, 2011. 